
\title{
25 Research Square \\ Life Expectancy of Older People Living in Aged Care Facilities after a Hip Fracture
}

\section{Maggie Killington \\ Flinders University \\ lan Cameron \\ University of Sydney \\ Raymond Li \\ Monash University \\ Susan Kurrle \\ University of Sydney \\ Maria Crotty \\ Flinders University}

Enwu Liu ( $\square$ enwu.liu@acu.edu.au )

Australian Catholic University

\section{Research Article}

Keywords: life expectancy, surgery, residential aged care facilities

Posted Date: December 21st, 2020

DOI: https://doi.org/10.21203/rs.3.rs-127980/v1

License: (c) (i) This work is licensed under a Creative Commons Attribution 4.0 International License.

Read Full License 


\section{Life expectancy of older people living in Aged Care Facilities after a hip fracture}

Enwu Liu ${ }^{1,6}$, Maggie Killington ${ }^{2}$, Ian D Cameron ${ }^{3}$, Raymond $\mathrm{Li}^{4}$, Susan Kurrle ${ }^{5}$, Maria Crotty ${ }^{6}$

${ }^{1}$ Mary Mackillop Institute for Health Research, Australian Catholic University, Melbourne, Victoria, Australia

${ }^{2}$ College of Nursing and Health Sciences, Flinders University, Adelaide, South Australia, Australia

${ }^{3}$ John Walsh Centre for Rehabilitation Research, Faculty of Medicine and Health, University of Sydney, Kolling Institute, St Leonards, NSW, Australia

${ }^{4}$ Monash School of Medicine, Monash University, Melbourne, Victoria, Australia

${ }^{5}$ Curran Ageing Research Unit, Faculty of Medicine and Health, University of Sydney and Hornsby Ku-ring-gai Hospital, Hornsby NSW, Australia

${ }^{6}$ College of Medicine and Public Health, Flinders University, Adelaide, South Australia, Australia 


\begin{abstract}
Little is known about life expectancy in nursing home residents with hip fracture. We assessed life expectancy of 240 residents of residential aged care facilities who were aged more than 70 years old and experienced recent hip fracture treated with surgery. 149 deaths occurred over a mean follow-up of 1.2 years. Being female (coefficient $(\beta)=0.86,95 \%$ confidence interval $(\mathrm{CI}): 0.39,1.34 ; \mathrm{p}=0.0004)$ was associated with longer life expectancy. Increased age was associated with shorter life expectancy ( $\beta=-0.06,95 \%$ CI: -0.10 to -0.02 , $\mathrm{p}=0.0043)$. Relative to severe cognitive impairment, normal or mild-cognitive impairment $(\beta=1.18,95 \%$ CI: 0.05 to $2.31, p=0.0414)$ and moderate cognitive impairment $(\beta=0.56,95 \%$ CI: 0.07 to $1.04, \mathrm{p}=0.0237$ ) were associated with longer life expectancy. Mortality rate within three months after hip fracture was 118 cases per 100 person-years while the mortality rate for the whole study period was 51.3 deaths per 100 person-years. For females with hip fracture, life expectancy was 8.2 years at 70 years of age; 4.8 years at 80 years of age; and 2.8 years at 90 years of age. For males with hip fracture, life expectancy was 3.8 years, 2.2 years and 1.3 years at 70, 80 and 90 years of age, respectively.
\end{abstract}


Population ageing and potential increases in age-related conditions which are associated with disability are widely recognized concerns. One such condition is osteoporotic fracture, particularly hip fracture, which has the greatest impact on health-related quality of life. (1) Older adults contribute social, cultural and economic resources to societies, thus issues that impair their ability to sustain these contributions warrant examination. It is estimated that 1.6 million hip fractures occur worldwide each year and by 2050 this number could reach between 4.5 million and 6.3 million. $(2,3)$ Hip fracture poses a significant economic burden worldwide.(4) Across Australian and New Zealand, more than 25,000 people break their hip each year with an estimated cost of 1 billion dollar annually.(5) In the US, it is estimated that by the year 2025, the annual cost of fractures associated with osteoporosis will be $\$ 25.3$ billion and hip fractures will account for $72 \%$ of these costs since hip fracture is most strongly associated with high morbidity and mortality rates.(6) While it is well known that hip fracture is associated with increased mortality in both sexes (7-9), little is known about life expectancy in nursing home residents with hip fracture. Life expectancy is a statistical measure of the number of years that a human expects to live based on one's current age and other demographic factors. Life expectancy is a key indicator used to assess mortality trends, disease burden, overall health status of a population and monitor trends in health care over time used by the World Health Organization (WHO).(10)

The Southern Adelaide Co-ordinated Regional Hip and Debility Rehabilitation Programme to Improve Quality of Life (SACRED) was a randomised clinical trial which examined whether providing rehabilitation in nursing care facilities for people who were recovering from hip fracture surgery improved quality of life and mobility at 4 weeks and 12 months. The primary outcomes of the trial were mobility and quality of life. The main study was conducted between June 2012 and December 2014, for mortality, the last follow up was extended to December 2015. The detailed descriptions of the trial and main results were reported elsewhere.(11) The objective of this analysis is to assess the life expectancy of people 70 and older after hip fracture and identify factors influencing the survival time.

\section{Methods}

\section{Study design and participants}

We performed secondary analyses using the data from the Southern Adelaide Co-ordinated Regional Hip and Debility Rehabilitation Programme to Improve Quality of Life trial (SACRED). The trial was conducted between June 2012 and December 2014; for mortality data, the last follow up was 18 December 2015. Participants were medically stable residential aged care facility residents aged 70 years or older who had experienced a recent, surgically treated hip fracture and were ambulant prior to their fracture either without assistance, with aids, or with the assistance of one other person. Participants unable to provide informed consent or obtain consent from a suitable proxy, had pathological and peri-prosthetic fractures, had a terminal illness and were receiving palliative care, had a hip fracture treated non-surgically or were unable to follow a one-step command due to cognitive impairment at recruitment were excluded from the study.(11) 


\section{Outcomes}

The outcome variable was survival time after hip fracture, calculated as date of death (all cause) minus date of baseline hip fracture. For patients surviving past 18 December 2015, the censored follow up time was calculated as 18 December 2015 minus the date of baseline hip fracture. For patients who were lost to follow up or withdrew, survival time was calculated as date of last contact minus date of baseline hip fracture.

\section{Covariates}

All covariates were measured at baseline: age; BMI; cognition as measured by Mini-Mental State Examination (MMSE); any previous fractures; previous hip fractures; surgery types and randomised group. All measurements and data collection were performed by the researchers or trained nurses for the trial.

\section{Statistical analyses}

Kaplan-Meier plots and log-rank tests were used to compare survival distributions across different groups. Weibull accelerated failure time (AFT) regression was chosen to investigate the associations between covariates and the survival time. Weibull AFT model was used to calculate life expectancy as it can produce robust results in ageing research.(12) The Weibull AFT model was specified as:

$$
\log \left(t_{i}\right)=\beta_{0}+\beta_{1} x_{i 1}+\cdots+\beta_{p} x_{i p}+\sigma \varepsilon_{i}=\boldsymbol{x}_{\boldsymbol{i}}^{\prime} \boldsymbol{\beta}+\sigma \varepsilon_{i}
$$

where subject $\mathrm{i}(\mathrm{i}=1,2, \ldots \mathrm{n})$ had $\mathrm{p}$ covariates $x_{i 1}, x_{i 2}, \ldots x_{i p}$ and possibly censored survival time $t_{i}, \sigma$ was the scale parameter, $\boldsymbol{\beta}=\left(\beta_{0}, \ldots, \beta_{p}\right)$ were the regression coefficients of covariates, $\varepsilon_{1} \ldots \varepsilon_{n}$ were independent and identically distributed according to the Gumbel distribution. $(13,14)$ Life expectancy was calculated as the expected value of survival time, $\mathrm{E}(\mathrm{T})=\exp \left(\boldsymbol{x}_{\boldsymbol{i}}^{\prime} \boldsymbol{\beta}\right) \Gamma(\sigma+1)$ where the Gamma function has the form $\Gamma(\mathrm{z})=$ $\int_{0}^{+\infty} x^{z-1} e^{-x} d x$

For sensitivity analysis, a Cox proportional hazards regression model was used to investigate the associations between covariates and mortality and results were compared with the results of the Weibull AFT model.

Analyses were performed using SAS 9.4 (SAS Institute, Cary, NC) and RStudio 1.2.5001 with R 3.6.3(RStudio, Inc. Boston, MA)

\section{Ethics approval}

The SACRED trial was registered on the Australian and New Zealand Clinical Trials Registry, registration number: ACTRN12612000112864. The Southern Adelaide Clinical Human Research Ethics Committee granted ethics approval for the secondary analysis of the trial and granted a waiver of informed consent (Application Number: 276.20). All research 
activities were carried out in accordance with the guidelines and regulations of the Australian National Health and Medical Research Council (NHMRC).

\section{Results}

A total of 240 participants of whom $178(74.2 \%)$ were female and $62(25.8 \%)$ were male were included in the study. The mean baseline age of participants was 88.6 (SD,5.6) years, ranging from 70 to 101 years. The mean baseline mini-mental state examination (MMSE) score was 8.0 (SD,7.8); $7.8 \%$ of participants had normal cognition or mild cognitive impairment, 33.8\% suffered moderate cognitive impairment and 58.7\% suffered severe cognitive impairment. The mini-nutritional assessment score was 5.3(SD,2.3). The mean BMI was $25.2(\mathrm{SD}, 4.9) \mathrm{kg} / \mathrm{m}^{2}$ with $5.4 \%$ underweight, $46.6 \%$ normal, $31.2 \%$ overweight and $16.7 \%$ obese. Ninety-four participants had experienced a previous fracture of any type and 32 had experienced a previous hip fracture. The most common surgery was intramedullary nailing $(36.3 \%)$ and three participants had total hip replacement. Table 1 shows the baseline characteristics of participants.

The mean follow-up time for participants was 1.2 years, median was 1.1 years with range from 0.06 to 3.6 years. In total, 149 deaths occurred during the follow-up period. KaplanMeier curves (Figure 1) showed that being female (log rank: $\mathrm{p}=0.0071)$, being of younger age (log rank: 0.0214) and having a higher MMSE score (log rank: 0.0045) were associated with better survival. The survival curves were steeper (i.e faster decline) early in the follow up period indicating that mortality was highest close to the time of hip fracture. Mortality rate was 118 deaths per 100 person-years within 3 months while the mortality rate of the whole study period (3.6 years) was 51.3 deaths per 100 person-years.

Table 2 showed being female indicated longer life expectancy (coefficient $(\beta)=0.86,95 \%$ confidence interval $(\mathrm{CI}): 0.39$ to $1.34, \mathrm{p}=0.0004)$. Older age was associated with shorter life expectancy $(\beta=-0.06,95 \%$ CI: -0.10 to $-0.02, p=0.0043)$. Relative to severe cognitive impairment, normal or mild-cognitive impairment $(\beta=1.18,95 \% \mathrm{CI}$ : 0.05 to $2.31, \mathrm{p}=0.0414)$ and moderate cognitive impairment $(\beta=0.56,95 \% \mathrm{CI}$ : 0.07 to $1.04, \mathrm{p}=0.0237)$ were associated with longer life expectancy. Randomisation groups, nutritional status, BMI, previous fractures of any type, previous hip fracture, and different surgery types were not associated with life expectancy.

Using the Weibull AFT model, we calculated life expectancy for different ages by sex. For females who underwent surgical treatment for hip fracture, estimated life expectancy would be 8.2 years for those aged 70 years at the time of fracture, 4.8 years for those aged 80 years, and 2.8 years for those aged 90 years. For male patients, estimated life expectancy was 3.8 years for those aged 70 years, 2.2 years for those aged 80 years and 1.3 years for those aged 90 years. (Figure 2 ).

Results of sensitivity analysis testing the same covariates in the Weibull AFT model in a multivariable Cox regression model did not yield different results. All estimates were consistent with the Weibull AFT model (in terms of association, direction and significance) (Table 3). 


\section{Discussion}

In this longitudinal study of 240 hip fracture patients we found that older age, male gender and greater impairment of cognition were associated with reduced life. Life expectancy of hip fracture patients living in nursing care facilities was lower than in the general Australian population especially for those younger patients. This study also found that mortality rate was much higher immediately following the hip fracture.

Life expectancy is defined as the average number of years a group of people is expected to live at a certain age, comparing hip fracture patients' life expectancy with that of the general population could show a straightforward impact of hip fracture on the population and the disease burden. The Treasurer of the Commonwealth of Australia estimated that in 2015 for a 70 year old female the life expectancy was 19.3 years (i.e. at 70 years old she was expected to live to 89.3 years) and for a 70 year old male the life expectancy was 16.9 years. (16) Therefore, the life expectancy of a 70 year old female hip fracture patient living in an nursing care facility could be $11(19.3-8.2=11.1)$ years shorter than that of the Australian general population, and it could be 13 years $(16.9-3.8=13.1)$ shorter for a 70 year old man.

Studies showed that women had a much higher risk for hip fracture than men, but men had much higher mortality than women after hip fractures. (17-21) Our study found that men's hazard rate for death was about twice that of women $(\mathrm{HR}=1.98)$. The study also found that if a hip fracture happened at a younger age, males would have much shorter life expectancy than females, however the difference decreased at older ages. Previous studies have found cognitive impairment to be a major risk factor for mortality after hip fracture and this was confirmed by our study.(22, 23) The relationship between mortality and BMI after hip fracture was not consistent; some studies suggested that being overweight or obese were protective factors for mortality after hip fracture, $(24,25)$ however, Akinleye et al followed 15,108 patients who underwent surgery for hip fracture over a five year period and found that either extreme of the BMI spectrum had the highest mortality rates.(26) In our study we did not find an association between BMI and mortality after hip fracture in these older patients. We did not find any association between the type of hip surgery and life expectancy, this result was consistent with a retrospective registry-based cohort study of 14,932 patients undergoing hip fracture surgery in Sweden.(27)

Mortality rate after hip fracture is associated with time since injury. Kanis et al showed that mortality rate after a hip or vertebral fracture is non-linear; the rate slows down significantly with time. $(28,29)$ We found the same phenomenon as the mortality rate within three months after hip fracture was more than 2 times higher $(118 / 51.3 \approx 2.3)$ than the whole study period. This trend suggests that intervention at an earlier time might prevent excessive deaths.(30)

This study had several strengths. The commencement of follow up and baseline characteristics of the patients were well defined and accurately measured. The follow-up rate was high and patients who were lost follow-up and withdrew from the study were well documented. Our study directly calculated the survival time which is the most natural measure for both clinicians and patients. Our study has limitations. Firstly, the inclusion and 
exclusion criteria of the clinical trial may reduce the generalisability of our results. Secondly, the life expectancy after hip fracture was only calculated by age and gender. Thirdly our sample size is relatively small. Using our model, life expectancy for more specific groups can be calculated, further studies with a much bigger sample size may provide a more comprehensive and specific life expectancy profile for hip fracture patients.

\section{Conclusions}

Overall, our data suggest that age, gender and cognition were associated with life expectancy of hip fracture patients. The life expectancy of hip fracture patients living in aged care facilities was much lower than that of the general Australian population as would be expected with this very disabled group of older people. Hip fracture occurring at a younger age in this population may cause more loss of life expectancy. The mortality rate was much higher immediately after hip fracture, but the speed of mortality decreased with time suggesting that interventions to decrease mortality should target the earlier period.

\section{Data availability}

The data that support the findings of this study are available from Dr Enwu Liu or Professor Maria Crotty (Maria.Crotty@sa.gov.au), upon reasonable request and ethnic approval from the Southern Adelaide Clinical Human Research Ethics Committee. 


\section{References}

1. Svedbom A, Borgstom F, Hernlund E, Strom O, Alekna V, Bianchi ML, et al. Quality of life for up to 18 months after low-energy hip, vertebral, and distal forearm fractures-results from the ICUROS. Osteoporos Int. 2018;29(3):557-66.

2. Gullberg B, Johnell O, Kanis J. World-wide projections for hip fracture. Osteoporosis international. 1997;7(5):407-13.

3. Cooper C, Campion G, Melton L. Hip fractures in the elderly: A world-wide projection. Osteoporosis International. 1992;2(6):285-9.

4. Williamson S, Landeiro F, McConnell T, Fulford-Smith L, Javaid MK, Judge A, et al. Costs of fragility hip fractures globally: a systematic review and meta-regression analysis. Osteoporosis International. 2017;28(10):2791-800.

5. ANZHFR. Annual Report of Hip Fracture Care 2019, Australian and New Zealand Hip Fracture Registry, August 2019.

6. Adeyemi A, Delhougne G. Incidence and Economic Burden of Intertrochanteric Fracture: A Medicare Claims Database Analysis. JBJS Open Access. 2019;4(1).

7. Katsoulis M, Benetou V, Karapetyan T, Feskanich D, Grodstein F, Pettersson - Kymmer U, et al. Excess mortality after hip fracture in elderly persons from Europe and the USA: the CHANCES project. Journal of internal medicine. 2017;281(3):300-10.

8. Kilci O, Un C, Sacan O, Gamli M, Baskan S, Baydar M, et al. Postoperative mortality after hip fracture surgery: a 3 years follow up. PLoS One. 2016;11(10):e0162097.

9. Farahmand BY, Michaelsson K, Ahlbom A, Ljunghall S, Baron JA. Survival after hip fracture. Osteoporosis International. 2005;16(12):1583-90.

10. Teeraananchai S, Kerr S, Amin J, Ruxrungtham K, Law M. Life expectancy of HIV - positive people after starting combination antiretroviral therapy: a meta - analysis. HIV medicine. 2017;18(4):256-66.

11. Crotty M, Killington M, Liu E, Cameron ID, Kurrle S, Kaambwa B, et al. Should we provide outreach rehabilitation to very old people living in Nursing Care Facilities after a hip fracture? A randomised controlled trial. Age and ageing. 2019;48(3):373-80.

12. Swindell WR. Accelerated failure time models provide a useful statistical framework for aging research. Experimental gerontology. 2009;44(3):190-200.

13. Lai C-D. Generalized weibull distributions. Generalized Weibull Distributions: Springer; 2014. p. 23-75.

14. Liu E, Lim K. Using the Weibull accelerated failure time regression model to predict time to health events. bioRxiv. 2018:362186.

15. Artin E. The gamma function: Courier Dover Publications; 2015.

16. 2015 intergenerational report, Australia in 2055. Hockey J, Australia T, editors. Parkes, A.C.T: Treasury; 2015.

17. Lobo E, Marcos G, Santabárbara J, Salvador-Rosés H, Lobo-Escolar L, De la Cámara C, et al. Gender differences in the incidence of and risk factors for hip fracture: A 16-year longitudinal study in a southern European population. Maturitas. 2017;97:38-43.

18. Sullivan KJ, Husak LE, Altebarmakian M, Brox WT. Demographic factors in hip fracture incidence and mortality rates in California, 2000-2011. J Orthop Surg Res. 2016;11:4.

19. Alvarez-Nebreda $M L$, Jiménez $A B$, Rodríguez $P$, Serra JA. Epidemiology of hip fracture in the elderly in Spain. Bone. 2008;42(2):278-85.

20. Kannegaard PN, van der Mark S, Eiken P, Abrahamsen B. Excess mortality in men compared with women following a hip fracture. National analysis of comedications, comorbidity and survival. Age and ageing. 2010;39(2):203-9.

21. Kristensen PK, Johnsen SP, Mor A, Thillemann TM, Pedersen AB. Is the higher mortality among men with hip fracture explained by sex-related differences in quality of in-hospital care? A population-based cohort study. Age and ageing. 2017;46(2):193-9. 
22. Schaller F, Sidelnikov E, Theiler R, Egli A, Staehelin H, Dick W, et al. Mild to moderate cognitive impairment is a major risk factor for mortality and nursing home admission in the first year after hip fracture. Bone. 2012;51(3):347-52.

23. Tarazona - Santabalbina FJ, Belenguer - Varea Á, Rovira Daudi E, Salcedo Mahiques E, Cuesta Peredó D, Doménech - Pascual JR, et al. Severity of cognitive impairment as a prognostic factor for mortality and functional recovery of geriatric patients with hip fracture. Geriatrics \& gerontology international. 2015;15(3):289-95.

24. Prieto - Alhambra D, Premaor MO, Avilés FF, Castro AS, Javaid MK, Nogués X, et al. Relationship Between Mortality and BMI After Fracture: A Population - Based Study of Men and Women Aged $\geqslant 40$ Years. Journal of bone and mineral research. 2014;29(8):1737-44.

25. Flodin L, Laurin A, Lökk J, Cederholm T, Hedström M. Increased 1-year survival and discharge to independent living in overweight hip fracture patients. Acta orthopaedica. 2016;87(2):146-51.

26. Akinleye SD, Garofolo G, Culbertson MD, Homel P, Erez O. The Role of BMI in Hip Fracture Surgery. Geriatr Orthop Surg Rehabil. 2018;9:2151458517747414.

27. Åhman R, Siverhall PF, Snygg J, Fredrikson M, Enlund G, Björnström K, et al. Determinants of mortality after hip fracture surgery in Sweden: a registry-based retrospective cohort study. Scientific reports. 2018;8(1):15695.

28. Johnell O, Kanis J, Oden A, Sernbo I, Redlund-Johnell I, Petterson C, et al. Mortality after osteoporotic fractures. Osteoporosis International. 2004;15(1):38-42.

29. Kanis J, Johansson H, Harvey N, Lorentzon M, Liu E, Borgström F, et al. Correspondence in response to OSIN-D-18-00831 quantifying imminent risk. Osteoporosis International.

2019;30(2):525-6.

30. Kanis J, Harvey N, McCloskey E, Bruyère $\mathrm{O}$, Veronese $\mathrm{N}$, Lorentzon $\mathrm{M}$, et al. Algorithm for the management of patients at low, high and very high risk of osteoporotic fractures. Osteoporosis International. 2019. 


\section{Acknowledgements}

The authors thank Dr Karen Lim for the editing of this manuscript.

\section{Author contributions}

E.L., I.D.C., S.K. and M.C. designed the study. E.L. had full access to the dataset and analysed the data. M.K. provided the data had full access to the dataset. E.L. and R.L. drafted the manuscript and all authors provided critical revisions and approved the final submitted version.

\section{Corresponding author}

Correspondence to Enwu Liu (enwu.liu@acu.edu.au)

\section{Funding}

This SCARED trial was supported by funding provided by the National Health and Medical Research Council (NHMRC) Partnership Centre on Dealing with Cognitive and Related Functional Decline in Older People (grant no. GNT9100000). There was no funding for the secondary analysis of the trial.

\section{Competing interests}

The authors declare no competing interests. 
Table 1. Baseline characteristics of the study population. Values are numbers (percentages) unless stated otherwise

\begin{tabular}{|c|c|}
\hline Baseline characteristics & $\begin{array}{l}\text { Whole population } \\
\qquad(n=240)\end{array}$ \\
\hline \multicolumn{2}{|l|}{ Group } \\
\hline Intervention & 119(49.6) \\
\hline Control & $121(50.4)$ \\
\hline \multicolumn{2}{|l|}{ Gender } \\
\hline Female & $178(74.2)$ \\
\hline Male & $62(25.8)$ \\
\hline Age-years, mean (SD) & $88.6(5.6)$ \\
\hline 70 to 79 & $16(6.6)$ \\
\hline 80 to 89 & $118(49.2)$ \\
\hline 90 to 101 & $106(44.2)$ \\
\hline Mini-Mental State Examination, mean (SD) & $8.0(7.8)$ \\
\hline Normal or mild-cognitive impairment (21-30) & $18(7.5)$ \\
\hline moderate-cognitive impairment (10-20) & $81(33.8)$ \\
\hline severe cognitive impairment $(<10)$ & $141(58.7)$ \\
\hline Mini-Nutritional Assessment, mean (SD) & $5.3(2.3)$ \\
\hline BMI, mean (SD) & $25.2(4.9)$ \\
\hline Underweight $(<18.5)$ & $12(5.4)$ \\
\hline Normal or Healthy Weight (18.5-24.9) & $103(46.6)$ \\
\hline Overweight (25.0 - 29.9) & $69(31.2)$ \\
\hline Obese $(\geq 30)$ & $37(16.7)$ \\
\hline \multicolumn{2}{|l|}{ Previous any fractures } \\
\hline Yes & $94(39.2)$ \\
\hline No & $146(60.8)$ \\
\hline \multicolumn{2}{|l|}{ Previous hip fractures } \\
\hline Yes & $32(13.3)$ \\
\hline No & $208(86.7)$ \\
\hline \multicolumn{2}{|l|}{ Type of surgery at baseline } \\
\hline Sliding hip screw & 23(9.6) \\
\hline Intramedullary nail & $87(36.3)$ \\
\hline Internal fixation & $33(13.8)$ \\
\hline Cemented Hemiarthroplasty & $64(26.7)$ \\
\hline Uncemented Hemiarthroplasty & $30(12.5)$ \\
\hline Total hip replacement & $3(1.25)$ \\
\hline
\end{tabular}


Table 2. Weibull AFT model assessment of the effect of covariates on survival time

\begin{tabular}{|c|c|c|}
\hline Variables & Coefficient $\beta$ (95\% Cl) & P value \\
\hline \multicolumn{3}{|l|}{ Group } \\
\hline Control & $0.35(-0.10$ to 0.80$)$ & 0.1276 \\
\hline Intervention & 0 & \\
\hline \multicolumn{3}{|l|}{ Gender } \\
\hline Female & $0.86(0.39$ to 1.34$)$ & 0.0004 \\
\hline Male & 0 & \\
\hline Age & $-0.06(-0.10$ to -0.02$)$ & 0.0043 \\
\hline \multicolumn{3}{|l|}{ Mini-Mental State Examination } \\
\hline Normal or mild-cognitive impairment (21 to 30 ) & $1.18(0.05$ to 2.31$)$ & 0.0414 \\
\hline moderate-cognitive impairment (10 to 20 ) & $0.56(0.07$ to 1.04$)$ & 0.0237 \\
\hline severe cognitive impairment $(<10)$ & 0 & \\
\hline Mini-Nutritional Assessment & $0.01(-0.09$ to 0.11$)$ & 0.8011 \\
\hline \multicolumn{3}{|l|}{ BMI } \\
\hline Obese $(\geq 30)$ & $0.60(-0.09$ to 1.29$)$ & 0.0864 \\
\hline Overweight (25.0 to 29.9 ) & $0.11(-0.41$ to 0.62$)$ & 0.6799 \\
\hline Under weight $(<18.5)$ & $0.11(-0.81$ to 1.03$)$ & 0.8103 \\
\hline Normal (18.5 to 24.9 ) & 0 & \\
\hline \multicolumn{3}{|l|}{ Previous any fractures } \\
\hline Yes & $0.19(-0.32$ to 0.69$)$ & 0.4709 \\
\hline No & 0 & \\
\hline \multicolumn{3}{|l|}{ Previous hip fractures } \\
\hline Yes & $0.10(-0.60$ to 0.79$)$ & 0.7854 \\
\hline No & 0 & \\
\hline \multicolumn{3}{|l|}{ Surgery type } \\
\hline Cemented Hemiarthroplasty & $-0.004(-0.73$ to 0.73$)$ & 0.9992 \\
\hline Internal fixation & $0.33(-0.52$ to 1.18$)$ & 0.4447 \\
\hline Intramedullary nail & $0.03(-0.68$ to 0.74$)$ & 0.9352 \\
\hline Sliding hip screw & $0.58(-0.34$ to 1.50$)$ & 0.2142 \\
\hline Total hip replacement & Not estimable & - \\
\hline Uncemented Hemiarthroplasty & 0 & \\
\hline
\end{tabular}


Table 3 Sensitivity analysis, Cox proportion model assessment of hazard ratios of covariates for death

\begin{tabular}{|c|c|c|}
\hline Variables & $\mathrm{HR}(95 \% \mathrm{Cl})$ & P value \\
\hline \multicolumn{3}{|l|}{ Group } \\
\hline Control & $0.76(0.53$ to 1.10$)$ & 0.1505 \\
\hline Intervention & 1 & \\
\hline \multicolumn{3}{|l|}{ Gender } \\
\hline Female & $0.51(0.34$ to 0.75$)$ & 0.0006 \\
\hline Male & 1 & \\
\hline Age & $1.05(1.02$ to 1.08$)$ & 0.0043 \\
\hline \multicolumn{3}{|l|}{ Mini-Mental State Examination } \\
\hline Normal or mild-cognitive impairment (21 to 30 ) & $0.37(0.15$ to 0.94$)$ & 0.0356 \\
\hline moderate-cognitive impairment (10 to 20 ) & $0.64(0.43$ to 0.95$)$ & 0.0256 \\
\hline severe cognitive impairment $(<10)$ & 1 & \\
\hline \multicolumn{3}{|l|}{ BMI } \\
\hline Obese $(\geq 30)$ & $0.85(0.39$ to 1.82$)$ & 0.6680 \\
\hline Overweight (25.0 to 29.9 ) & $0.94(0.61$ to 1.43$)$ & 0.7539 \\
\hline Under weight $(<18.5)$ & $0.63(0.36$ to 1.10$)$ & 0.1046 \\
\hline Normal (18.5 to 24.9$)$ & 1 & \\
\hline \multicolumn{3}{|l|}{ Previous any fractures } \\
\hline Yes & $0.86(0.56$ to 1.30$)$ & 0.4695 \\
\hline No & 1 & \\
\hline \multicolumn{3}{|l|}{ Previous hip fractures } \\
\hline Yes & $0.92(0.52$ to 1.63$)$ & 0.7787 \\
\hline No & 1 & \\
\hline \multicolumn{3}{|l|}{ Surgery type } \\
\hline Cemented Hemiarthroplasty & $0.98(0.54$ to 1.80$)$ & 0.9582 \\
\hline Internal fixation & $0.79(0.39$ to 1.59$)$ & 0.5100 \\
\hline Intramedullary nail & $0.97(0.54$ to 1.74$)$ & 0.9161 \\
\hline Sliding hip screw & $0.62(0.29$ to 1.34$)$ & 0.2243 \\
\hline Total hip replacement & Not estimable & _ \\
\hline Uncemented Hemiarthroplasty & 1 & \\
\hline
\end{tabular}



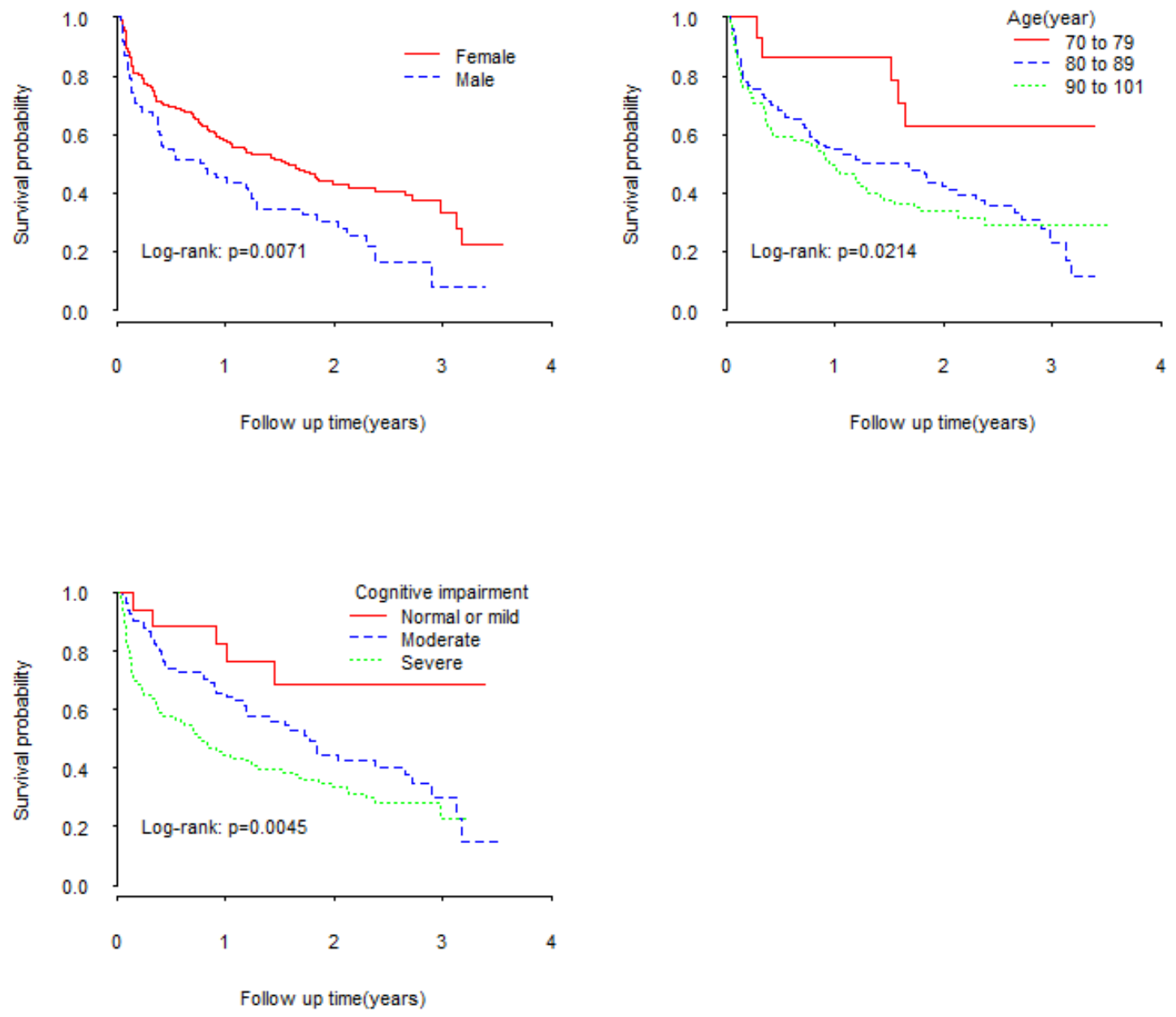

Figure 1 Kaplan-Meier survival plot after hip fracture 


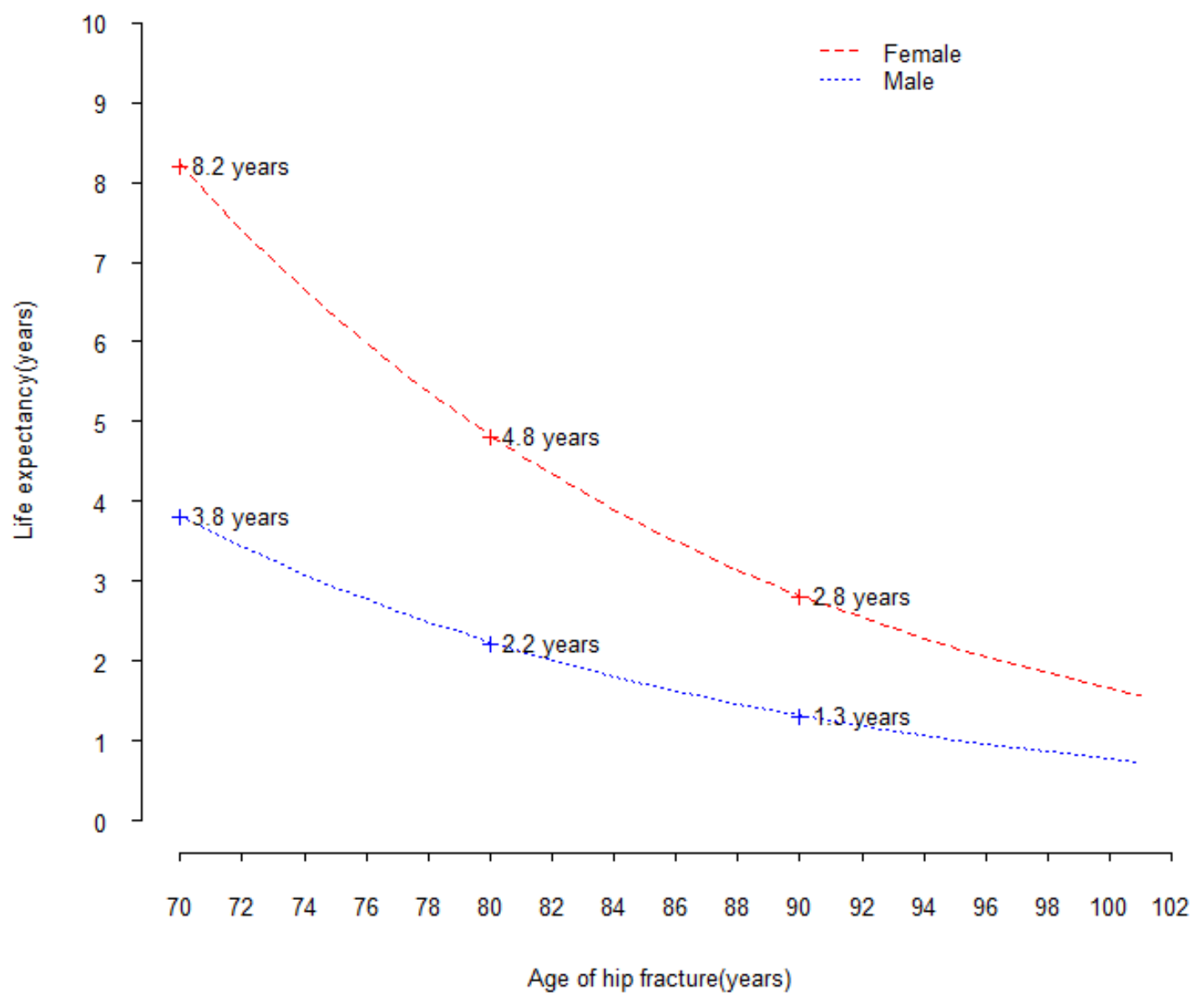

Figure 2 Life expectancy after hip fracture by age and gender 
Figures
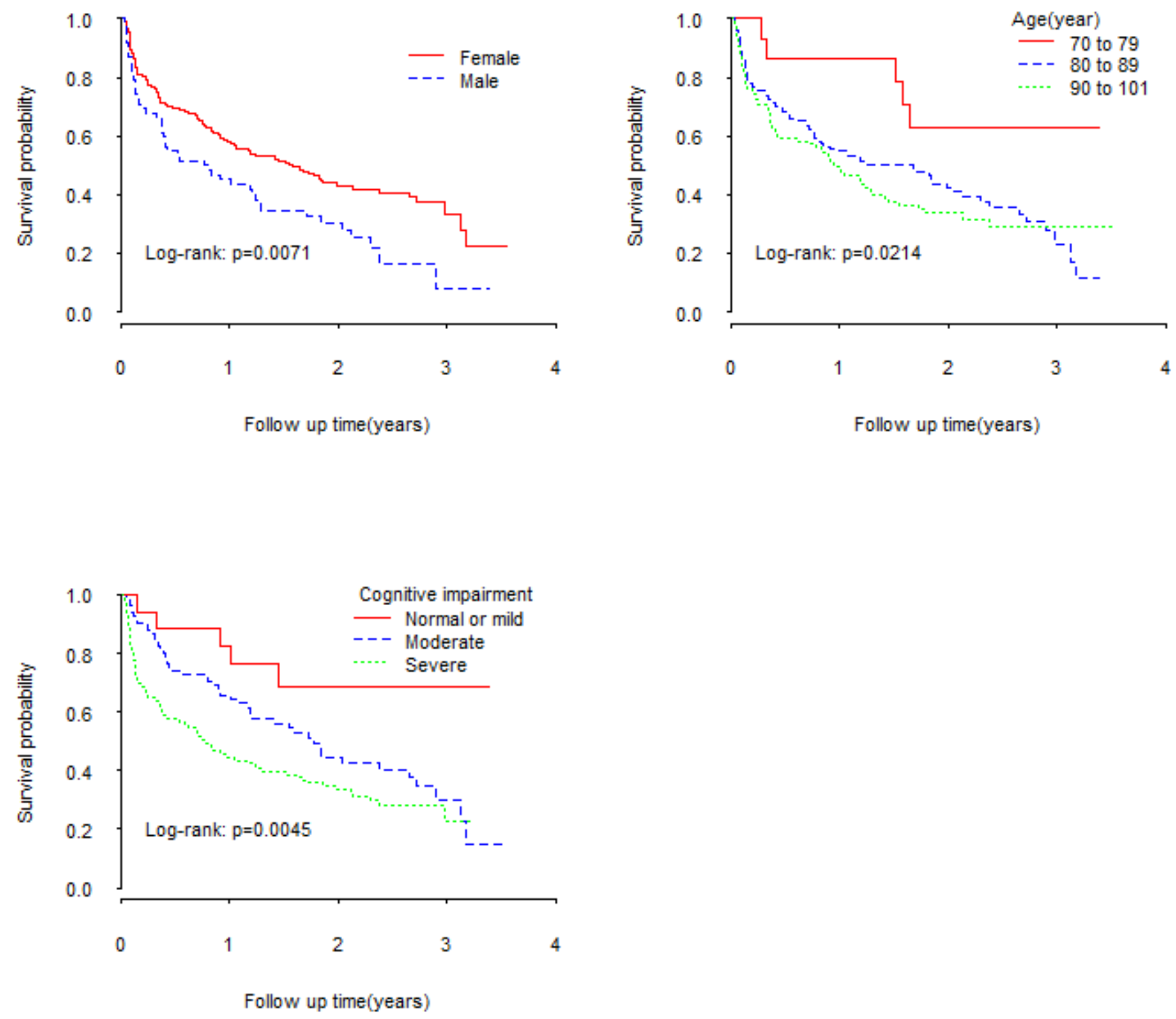

Figure 1

Kaplan-Meier survival plot after hip fracture 


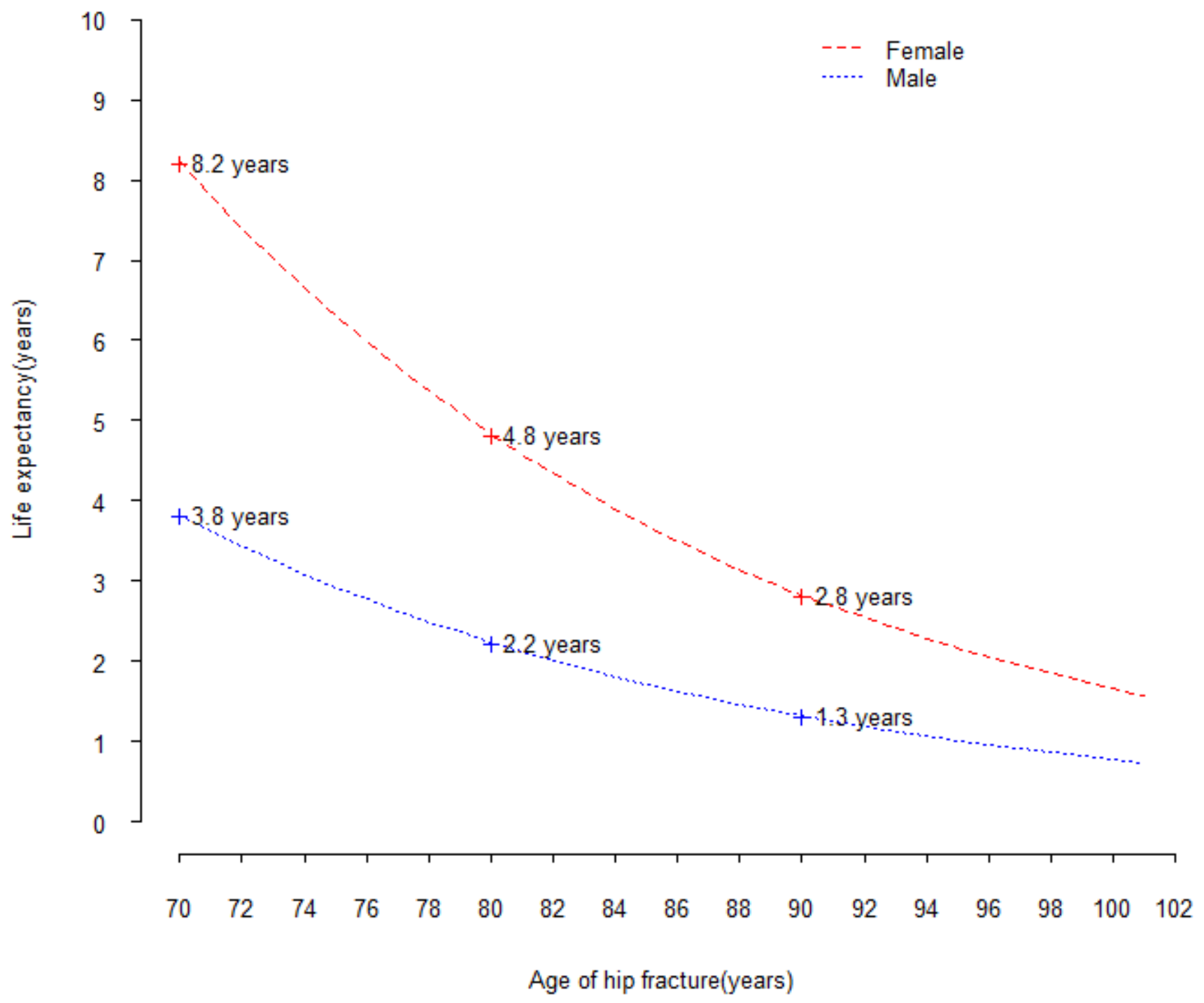

Figure 2

Life expectancy after hip fracture by age and gender 